\title{
Antegrade pressure measurement of urinary tract in children with persistent hydronephrosis
}

\author{
Patrícia Traballi de Carvalho Pegolo, Marcio Lopes Miranda, Sheila Kim, Antonio Gonçalves de Oliveira \\ Filho, Leonardo Oliveira Reis, Joaquim Murray Bustorff Silva \\ Division of Pediatric Surgery, Genitourinary Division (PTCP, MLM, SK, AGO, JMBS) and Urologic \\ Division (LOR), University of Campinas - UNICAMP, Campinas, SP, Brazil and Faculty of Medicine, \\ (LOR) Pontifical University of Campinas, PUC-Campinas, SP, Brazil
}

\section{ABSTRACT}

Introduction: Dilation of urinary tract occurs without the presence of obstruction. Diagnostic methods that depend on renal function may elicit mistaken diagnosis. Whitaker (1973) proposed the evaluation of urinary tract pressure submitted to constant flow. Other investigators proposed perfusion of renal pelvis under controlled pressure, making the method more physiological and reproducible. The objective of the present study was to evaluate the results of the anterograde pressure measurement (APM) of the urinary tract of children with persistent hydronephrosis after surgery suspected to present persistent obstruction.

Materials and Methods: Along 12 years, 26 renal units with persistent hydronephrosis after surgery (12 PUJ and 14 VUJ) were submitted to evaluation of the renal tract pressure in order to decide the form of treatment. Previous radionuclide scans with DTPA, intravenous pyelographies and ultrasounds were considered undetermined in relation to obstruction in 10 occasions and obstructive in 16. APM was performed under radioscopy through renal pelvis puncture or previous stoma. Saline with methylene blue + iodine contrast was infused under constant pressure of $40 \mathrm{~cm} \mathrm{H} 20$ to fill the urinary system. The ureteral opening pressure was measured following the opening of the system and stabilization of the water column.

Results: Among the 10 cases with undetermined previous diagnosis, APM was considered non-obstructive in two and those were treated clinically and eight were considered obstructive and were submitted to surgery. Among the 16 cases previously classified as obstructive, nine confirmed obstruction and were submitted to surgery. Seven cases were considered non-obstructive, and were treated clinically, with stable DMSA and hydronephrosis.

Conclusions: APM avoided unnecessary surgery in one third of the cases and was important to treatment decision in $100 \%$. We believe that this simple test is an excellent diagnostic tool when selectively applied mainly in the presence of functional deficit.

\section{ARTICLE INFO}

\section{Key words:}

Hydronephrosis; Kidney; Pyonephrosis; Urinary Tract; Whitaker test; obstruction; renal pelvis; percutaneous; functional deficit

Int Braz J Urol. 2012; 38: 448-55

Submitted for publication: January 31,2012

Accepted after revision: July 19, 2012

\section{INTRODUCTION}

Dilation of the upper urinary tract is a frequent finding in all pediatric ages. The distinction between obstructive and non-obstructive hydronephrosis is challenging for the urologic surgeon, mainly in patients already submitted to surgical treatment of reflux or obstruction. The dynamical diagnostic methods depend on the renal function and on the response to diuretics; in 
the presence of functional deficit, they may elicit mistaken diagnosis (1).

In 1973, Whitaker $(2,3)$ described the evaluation of the urinary tract pressure submitted to a constant flow, but with low reproducibility (4) and with many criticism $(5,6)$. In order to obtain a more physiological evaluation, other investigators proposed the perfusion of the renal pelvis under controlled pressure, obtaining a more precise and sensitive method (7); they defined the ureteral opening pressure the one in which the contrast surpass the suspected point of obstruction (8).

After approximately 40 years of study, there is still difficulty in ascertain precisely the existence of obstruction of the upper urinary tract in children with hydronephrosis and renal function deficit, making obligatory the need of other exams as urography and radionuclide renography (dynamic scintigraphy with DTPA - 99mTC diethylene-triamin-pentacetic acid), the last one considered the gold standard test for obstruction $(9,10)$. The urological magnetic resonance image combines anatomical and functional aspects without the use of radiation and many researches advocate that in a short period of time it will supersede radionuclide renography; however, its higher cost and the need of a collaborative child limit its use (11).

The antegrate pressure measurement of the upper urinary tract (APM), although invasive, is an important diagnostic tool for the decision-making of forms of treatment of children with persistent post-surgical hydronephrosis (12). This method is widely used in adults, but rarely in children. In our service, it has been used in the last decade.

The present study aims to evaluate the role of APM of the renal tract of children with persistent post-surgical hydronephrosis suspected of the presence of obstruction. We used a modified protocol of the originally proposed by Whitaker $(2,3)$ in order to make it more physiological and reproducible.

\section{MATERIALS AND METHODS}

This retrospective study was approved by the Local Ethical Committee (241/2010) and in- volved the analysis of the charts of the exams performed in a period of 12 years (1997-2008). Twenty and four children ( 3 months to 15 years old), with 26 renal units with persistent post-surgical hydronephrosis, 22 of which with low tubular function (12 anomalies of the pelviureteric junction - PUJ and 14 with anomalies of the vesicoureteric junction - VUJ) were submitted to 26 APM tests for evaluation of obstruction ( 2 children with bilateral anomalies of VUJ). All children were previously submitted to surgery for the correction of the detected anomalies, with a median period of time of 23.5 months and with post-operatory exams (intravenous pyelogram, renal ultrasound and 99mTCDTPA) considered obstructive or undetermined (Table-1). The undetermined pattern included cases with low excretion and gross hydronephrosis at the pyelogram although with passage of the dye beyond the suspected point of obstruction and/or functional deficit and low excretion, without exclusion of obstructive pattern at DTPA.

Children with persistent hydronephrosis without obstruction at 99mTC-DTPA were excluded as well as those who missed ambulatory follow-up. Among the selected children, 8 had been previously submitted to urinary diversion due to distal obstruction. Previous intravenous pyelograms, renal ultrasounds and 99mTc-DTPA scans showed undetermined pattern in 10 cases and obstructive in 16 (Table-1). Hydronephrosis was described according to the classification of the Society for Fetal Urology (13).

\section{Technique}

The test involved percutaneous puncture of renal pelvis with an epidural needle $18 \mathrm{G} / 1.3 \times 80$ $\mathrm{mm}$, under radioscopy (18 renal units) or via stoma previously installed (8 renal units) and infusion of saline at room temperature (Figure-1). All patients were submitted to general anesthesia, placed in lateral oblique recumbency, with an angle of approximately 45 degrees in relation to the operation table; a bladder catheter was inserted and all patients were well hydrated. In the patients without previous urinary diversion and hydronephrosis grades III/IV, renal pelvis was identified using anatomical reference points, through a single lumbar puncture, via postero-lateral access of the renal cortex in order 
Table 1 - Number of children with persistent hydronephrosis.

\begin{tabular}{|c|c|c|c|c|}
\hline & & PUJ (\%) & VUJ (\%) & Total (\%) \\
\hline Renal Units & & $12(46.2)$ & $14(53.8)$ & $26(100.0)$ \\
\hline Prenatal diagnosis & & $5(19.2)$ & $4(15.4)$ & $9(34.6)$ \\
\hline \multicolumn{2}{|l|}{ Previous diversion } & $3(11.5)$ & $5(19.2)$ & $8(30.7)$ \\
\hline \multicolumn{5}{|l|}{ Pre-APM diagnosis } \\
\hline & Obstructive & $5(19.2)$ & $11(42.3)$ & $16(61.5)$ \\
\hline & Undetermined & $7(27.0)$ & $3(11.5)$ & $10(38.5)$ \\
\hline \multirow[t]{4}{*}{ Hydronephrosis } & Grade & & & \\
\hline & II & $2(7.7)$ & $1(3.8)$ & $3(11.5)$ \\
\hline & III & $1(3.8)$ & $0(0)$ & $1(3.8)$ \\
\hline & IV & $9(34.6)$ & $13(50.0)$ & $22(84.6)$ \\
\hline
\end{tabular}

Figure 1 - Measurement of the Antegrade Pressure of the Upper Urinary Tract.

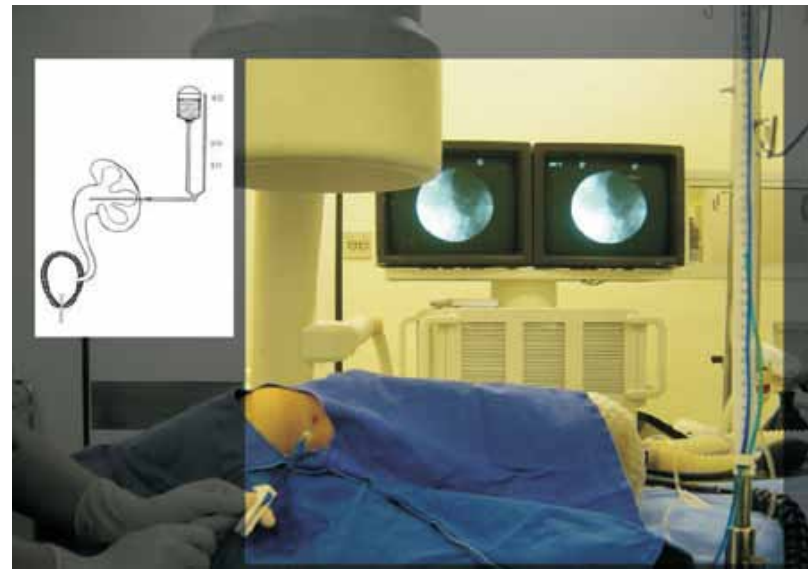

to reach the collecting system, avoiding the renal hilum lowering the risks of bleeding and leakage of urine, below the 12th rib, to avoid pneumothorax.

Intrarenal pelvis with a lower degree of hydronephrosis was accessed using radioscopy, after cystoscopy and ascending pyelogram. The pubic symphysis was considered the zero marker for the water column and the permeability of the system was tested by an increase of the pressure provoked by manual compression of the abdominal wall. For the infusion, it was used an Y system, using saline with methylen blue + iodine contrast (50\%), under a constant pressure of $40 \mathrm{~cm} \mathrm{H2O}$, until the complete filling of the renal tract under fluoroscopy. From that moment on, the infusion was stopped and the pressure of the renal tract was measured after stabilization of the water column.

The bladder catheter excluded the pressure of the lower urinary tract and allowed the observation of the flow of blue dyed saline. The pressure of the system was confirmed lowering the water column until flow cessation. The results were considered obstructive when the water column was stable and above $14 \mathrm{~cm} \mathrm{H} 20$, and non-obstructive, below or equal to $14 \mathrm{~cm} \mathrm{H} 20$. Individuals with three consecutive measures higher than $14 \mathrm{~cm} \mathrm{H2O}$ were considered obstructed. However, for those with lower pressures ( $<14 \mathrm{~cm} \mathrm{H2O})$, the infusion was maintained until the dye surpassed the suspected point of obstruction; at that moment, the pressure of the system was determined (ureteral opening pressure). Radiological characteristics were extremely important (anatomical and needle position) for the ending of the test and it was mandatory to be used throughout the test. The resistance of the catheters 
was not considered since the measurement of the urinary tract pressure was done intermittently and after interruption of the infusion (14).

\section{RESULTS}

From a total of 26 exams, 10 were performed in children with pre-operatory exams with undetermined results (Figure-2). In all patients the exam was able to discriminate obstructive and non-obstructive cases, guiding the choice of treatment. Among the 8 patients with obstruction, with median values of $30 \mathrm{~cm} \mathrm{H} 2 \mathrm{O}(10-50 \mathrm{~cm} \mathrm{H} 20), 7$ were reoperated (one ureterostomy, two new py-
Among the 16 exams performed in patients with previous diagnosis of obstruction (ultrasound/ intravenous pyelogram/99mTC-DTPA), in 9 the obstruction was confirmed and they were submitted to surgery (1 ureterostomy; 1 pyelostomy; 1 ureteral meatotomy; 1 ureteral reimplantation; 2 uretero-uretero-anastomosis; 1 pyelo-pyelic anastastomosis; 1 nephrostomy; 1 new pyeloplasty).

Seven tests were considered non-obstructive and clinically treated, without prejudice to function (according to DMSA) in a median follow-up of 7 years (Figure-2). Only one renal unit (anomaly of PUJ) presented pressure of $16 \mathrm{~cm} \mathrm{H2O}$ and was considered non-obstructive since this was

Figure 2 - Flowchart of cases and test results.

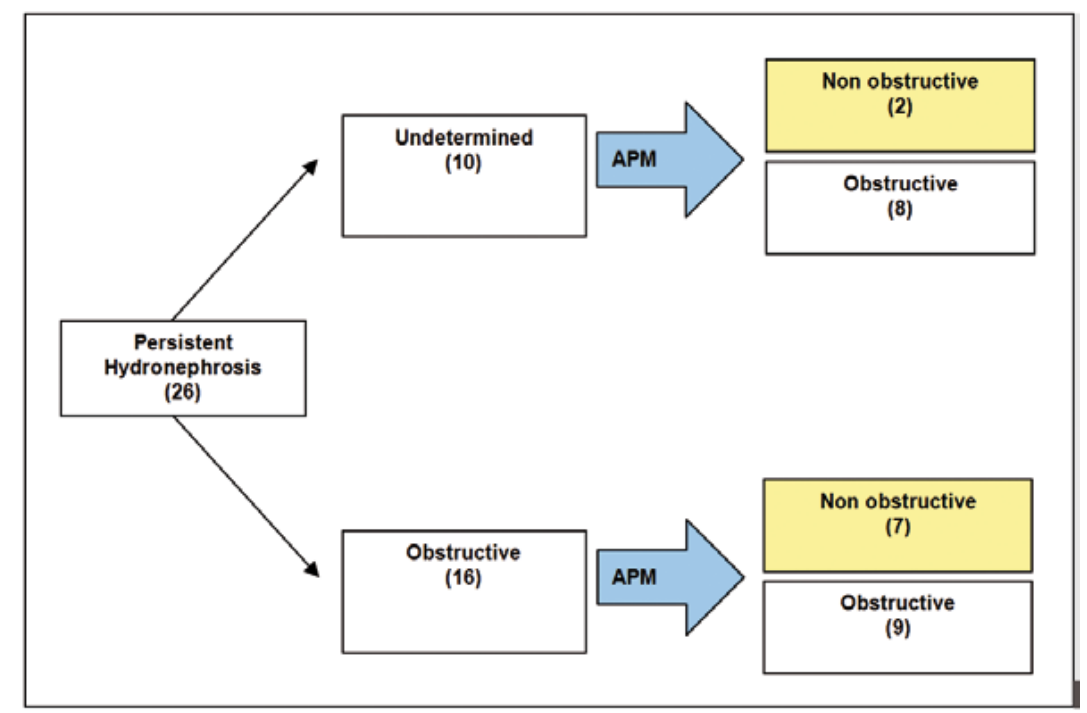

eloplasties, two uretero-calix-anastomosis and two endopyelotomies).

Only one was submitted to ureteral catheterization due to end-stage renal disease (posterior urethral valve). In two patients of this group, the test revealed non-obstructive hydronephrosis (10$14 \mathrm{~cm} \mathrm{H20),} \mathrm{avoiding} \mathrm{unnecessary} \mathrm{new} \mathrm{surgeries.}$ For those patients the treatment of choice was expectant and they were stable on the follow-up of 3 and 6 years. The grade of ultrasonographic dilation and tubular function (static renal scintigraphy with DMSA - dimercaptossuccinic acid) were stable. a patient with Prune-Belly Syndrome with high grade bilateral ureteral reflux. No patient showed worsening of renal function during follow-up (10 months - 12 years, median 63.4 months). When studying the nine renal units considered non-obstructive after the test and conservatively treated (median 77 months), tubular function remained stable even in the persistence of the hydronephrosis (Table-2).

There were no complications that needed treatment or hospitalization, in agreement with literature data regarding the procedure $(<1 \%)(15)$. 
Table 2 - Patients with test results considered non obstructive treated clinically.

\begin{tabular}{|c|c|c|c|c|c|c|c|c|}
\hline Patient & Diagnosis/ Surgery & USG & $\begin{array}{l}\text { DMSA(\%) } \\
\text { RK/LK }\end{array}$ & $\begin{array}{c}\text { DTPA } \\
\text { (RK/LK) }\end{array}$ & $\begin{array}{c}\text { Test } \\
\left(\mathrm{cmH}_{2} \mathrm{O}\right)\end{array}$ & $\begin{array}{c}\text { DMSA(\%) } \\
\text { RK/LK }\end{array}$ & Follow-up & $\begin{array}{c}\text { US } \\
\text { Post } \\
\text { surgical }\end{array}$ \\
\hline AFO & L PUJ /Pyeloplasty & G IV & $81 / 19$ & NO/I & 10 & $80 / 20$ & 3 years & GIV \\
\hline EBS & R PUJ /Pyeloplasty & GIII & $23 / 77$ & $0 / \mathrm{NO}$ & 10 & $24 / 76$ & 7 years & GIII \\
\hline IAS & $\begin{array}{l}\text { L PUJ (Prunne } \\
\text { Belly)/L Pyelostomy }\end{array}$ & G II & $4 / 96$ & $1 / 0$ & 16 & $0 / 100$ & 10 years & Gll \\
\hline KCRL & L PUJ/L Pyeloplasty & G IV & $62 / 38$ & $\mathrm{NO} / \mathrm{O}$ & 11 & $62 / 38$ & 5 years & GIV \\
\hline LSR & $\begin{array}{l}\text { R PUJ/R Pyeloplas- } \\
\text { ty + R nephrostomy }\end{array}$ & Gll & $92 / 8$ & $0 / 1$ & 10 & $91 / 9$ & 12 years & $\mathrm{Gl}$ \\
\hline JMM & $\begin{array}{l}\text { L VUJ/L reimplan- } \\
\text { tation }\end{array}$ & G IV & $79 / 21$ & NO/I & 14 & $78 / 22$ & 6 years & GIV \\
\hline LAT & $\begin{array}{c}\text { Bilateral VUJ / } \\
\text { Vesicostomy +R } \\
\text { Pyelostomy + L } \\
\text { Ureterostomy }\end{array}$ & $\begin{array}{l}\text { Exclusion/ } \\
\text { G IV }\end{array}$ & $\begin{array}{c}\text { Exclusion } \\
\text { RK }\end{array}$ & $1 / 0$ & 9 & $6 / 94$ & 2 years & GIV \\
\hline LMSC & $\begin{array}{l}\text { Bilateral VUR / Bila- } \\
\text { teral reimplantation }\end{array}$ & GIV /GII & $15 / 85$ & $0 / \mathrm{NO}$ & 10 & $21 / 79$ & 3 years & GIV \\
\hline TCB & $\begin{array}{c}\text { Bilateral PUJ /Pye- } \\
\text { Ioplasty +bilateral } \\
\text { nephrostomy }\end{array}$ & GII / G III & $46 / 54$ & - & 5 & $52 / 48$ & 10 years & GIII \\
\hline
\end{tabular}

Those with urinary diversion without proved obstruction at APM were submitted to reversion of diversion ( $\mathrm{n}=3$ nephrostomy withdrawal $/ \mathrm{n}=1$ closure of ureterostomy / $\mathrm{n}=1$ closure of pyelostomy) and only two maintained prophylaxis with antibiotics due to the presence of voiding disturbances.

\section{DISCUSSION}

The test proposed by Whitaker, that combines urodynamic and radiological aspects, was intended to differentiate residual obstructive hydronephrosis or recurrence due to dilation secondary to permanent changes, with five precise indications: persistent dilation of the upper urinary tract following surgical correction of obstruction, possible obstruction of pelviureteric and vesicoureteric junctions, safe withdrawal of urinary diversions, evaluation of primary defects of ureteral muscle and evaluation of the influence of bladder volume and pressure on the ureteral dynamics (16).

Just like him, several other authors tried to define the process of obstruction of the upper urinary tract however not correlating the grade of obstruction with the risk of renal damage (17). Our study was able to benefit children submitted to at least one surgical procedure that remained with hydronephrosis, or those with urinary diversion due to obstruction that needed surgery to withdraw the diversion.

In this study the test was safe and able to guide the treatment in all evaluated cases. In those previously classified as undetermined $(n-=10)$, the 
test was able to propose two different groups, those with obstruction $(\mathrm{n}=8)$ and those without obstruction $(n=2)$, that were clinically treated without the need of surgical intervention in a median follow up period of 4.5 years.

In cases with previous diagnosis of obstruction $(\mathrm{n}=16)$, it was observed a disparity between $99 \mathrm{~m}$ Tc-DTPA and the APM test $(18,19)$; the obstruction was confirmed in only nine renal units (56.3\%).

Wang et al. agreed that the renogram with only diuretics is not a reliable parameter for the diagnosis of obstructive hydronephrosis after surgery of renal units with functional deficit and they suggested that the measurement of the antero-posterior diameter and the evaluation of the renal function must be considered for the confirmation of the presence of obstruction (20).

None renal unit was lost during follow up, that ranged from 10 months to 12 years (median = 63.4 months) and only one child presented significant loss of renal function following pyeloplasty (pre-test). In this child, the dynamic radionuclide renogram after surgery was considered undetermined due to a gross functional deficit and the APM was considered obstructive, resulting in a uretero-calyx-anastomosis. After this procedure, the child is asymptomatic with stable renal function after one year of follow-up. Four patients presented end-stage renal disease at the moment of the test: one due to posterior urethral valve, two with Prune Belly Syndrome and high grade bilateral ureteral reflux and one patient with a solitary kidney with obstruction of the vesicoureteric junction.

All children maintained DMSA and serum creatinine levels stable, and were attended by a multidisciplinary team of pediatricians and nephrologists, and were non-dependent of dialysis. In spite of the chosen treatment (surgical or clinical), all children maintained their hydronephrosis during follow-up, although with stability of tubular function (DMSA) and absence of renal infections.

The main criticism of the test proposed initially by Whitaker was the low reproducibility mainly due to the high grade flow of infusion (10 $\mathrm{mL} / \mathrm{min}$.), leading to a non-real rise of the upper urinary tract pressure (17).
Ripley (1982) and Woodbury (1989) proposed the infusion of saline under constant pressure and presented high reproducibility with simple equipment. These tests were initially performed in animals without ureteral dilation, and in this situation, ureteral contraction in response to constant flow may have been more evident than in a chronically dilated ureter with atrophic ureteral musculature $(4,7)$.

The study of the ureteral opening pressure (by constant flow or pressure) has a high positive predictive value when above $14 \mathrm{~cm}$ $\mathrm{H} 2 \mathrm{O}$ (8). Otherwise, Veenboer and Jong showed a high negative predictive value (12). In the present study, all patients treated clinically had no progression of the obstruction (asymptomatic and without renal damage) in a follow-up that varied from 2 to 12 years.

In 1981, Newhouse et al. already advocated the proposal of a superior normal limit of the renal perfusion pressure of dilated patients (21). After that, several experimental studies showed that pressures on the renal system above $14 \mathrm{~cm}$ $\mathrm{H} 2 \mathrm{O}$ determined adverse alterations of the renal blood flow, glomerular filtration rate and tubular function; with pressures above $20 \mathrm{~cm} \mathrm{H} 20$ there was apoptosis and lowering of the vascular endothelial growth factor (22).

This study did not require urodynamic studies or complex mathematical formulae and avoided unnecessary surgeries in nine cases (34.6\%), guiding treatment in $100 \%$ of the cases, in agreement with the study of Lupton and George (23).

There were three modifications of the originally proposed test by Whitaker, without changing the results: 1 . Infusion with constant pressure without the need of an infusion pump (simplifying the test, with easily reproducible results); 2. Patient position (oblique lateral recumbency), and 3. Applying the tests in cases initially considered undetermined (15-22 cm H2O) as if obstructive, due to the maintenance of the dilation grade and persistence of urinary infection, without any prejudice to function or behavior (24).

Although with intrinsic limitations of a retrospective study, it was used a set of very simple, small, light and portable kit of apparatus, that 
can be reproducible in any hospital dedicated to pediatric patients.

\section{CONCLUSIONS}

Antegrate Pressure Measure is a safe diagnostic tool with minimal morbidity. The test guided the treatment of all cases and avoided unnecessary new surgeries in one third of the studied cases and helped understand the dynamic and radiological behavior of the upper urinary tract, with a considerable clinical value in the followup of children suspected with urinary obstruction. The test is an important tool to evaluate persistent post-surgical dilation of the urinary tract, when used selectively and mainly in the presence of functional deficit.

"That intangible art of clinical judgment must still dominate practice of medicine"

\section{ABBREVIATIONS}

DTPA: Diethylene triamin pentacetic acid

APM: Antegrade pressure measurement

USG: Ultrasonography

PUV: Posterior urethral valve

PUJ: Pelviureteric junction

VUJ: Vesicoureteric junction

DMSA: Dimercaptossuccinic acid

\section{CONFLICT OF INTEREST}

None declared.

\section{REFERENCES}

1. Whitaker RH, Buxton-Thomas MS: A comparison of pressure flow studies and renography in equivocal upper urinary tract obstruction. J Urol. 1984; 131: 446-9.

2. Whitaker $\mathrm{RH}$ : Methods of assessing obstruction in dilated ureters. Br J Urol. 1973; 45: 15-22.

3. Tchetgen MB, Bloom DA: Robert H. Whitaker and the Whitaker test: a pressure-flow study of the upper urinary tract Urology. 2003; 61: 253-6.

4. Ripley SH, Somerville JJ: Whitaker revisited. Br J Urol. 1982; 54: 594-8.
5. Ellis JH, Campo RP, Marx MV, Cohan RH, Platt JF, Sonda LP, et al.: Positional variation in the Whitaker test. Radiology. 1995; 197: 253-5.

6. Wentzell PG, Arnold AJ, Carty H, Rickwood AM: Two-needle modification of the Whitaker test. Br J Urol. 1988; 62: 388.

7. Woodbury PW, Mitchell ME, Scheidler DM, Adams MC, Rink RC, McNulty A: Constant pressure perfusion: a method to determine obstruction in the upper urinary tract. J Urol. 1989; 142: 632-5; discussion 667-8.

8. Fung LC, Churchill BM, McLorie GA, Chait PG, Khoury AE: Ureteral opening pressure: a novel parameter for the evaluation of pediatric hydronephrosis. J Urol. 1998; 159: 1326-30.

9. Senac MO Jr, Miller JH, Stanley P: Evaluation of obstructive uropathy in children: radionuclide renography vs. the Whitaker test. AJR Am J Roentgenol. 1984; 143: 11-5.

10. Lupton EW, Richards D, Testa HJ, Gilpin SA, Gosling JA, Barnard RJ: A comparison of diuresis renography, the Whitaker test and renal pelvic morphology in idiopathic hydronephrosis. Br J Urol. 1985; 57: 119-23.

11. Jones RA, Grattan-Smith JD, Little S: Pediatric magnetic resonance urography. J Magn Reson Imaging. 2011; 33: 510-26.

12. Veenboer PW, de Jong TP: Antegrade pressure measurement as a diagnostic tool in modern pediatric urology. World J Urol. 2011; 29: 737-41.

13. Fernbach SK, Maizels M, Conway JJ: Ultrasound grading of hydronephrosis: introduction to the system used by the Society for Fetal Urology. Pediatr Radiol. 1993; 23: 478-80.

14. Gill B, Levitt S, Kogan S, Reda E, Weiner S, Donner K: The dilated urinary tract in children. Prospective analysis with correlation of radiological, isotope, pressure perfusion and surgical findings. Br J Urol. 1988; 61: 413-9.

15. Pfister RC, Papanicolaou N, Yoder IC: Diagnostic morphologic and urodynamic antegrade pyelography. Radiol Clin North Am. 1986; 24: 561-71.

16. Jaffe RB, Middleton AW Jr:: Whitaker test: differentiation of obstructive from nonobstructive uropathy. AJR Am J Roentgenol. 1980; 134: 9-15.

17. Wåhlin N, Magnusson A, Persson AE, Läckgren G, Stenberg $A$ : Pressure flow measurement of hydronephrosis in children: a new approach to definition and quantification of obstruction. J Urol. 2001; 166: 1842-7.

18. Gonzalez R, Chiou R: The diagnosis of upper urinary tract obstruction in children: comparison of diuresis renography and pressure flow studies. J Urol. 1985; 133: 646-9.

19. Dacher J, Pfister C, Thoumas D, Véra P, Liard-Zmuda A, Chomant $\mathrm{J}$, et al.: Shortcomings of diuresis scintigraphy in evaluating urinary obstruction: comparison with pressure flow studies. Pediatr Radiol. 1999; 29: 742-7.

20. Wang TM, Chang PL, Kao PF, Hsieh ML, Huang ST, Tsui KH: The role of diuretic renography in the evaluation of obstructed hydronephrosis after pediatric pyeloplasty. Chang Gung Med J. 2004; 27: 344-50. 
21. Newhouse JH, Pfister RC, Hendren WH, Yoder IC: Whitaker test after pyeloplasty: establishment of normal ureteral perfusion pressures. AJR Am J Roentgenol. 1981; 137: 223-6.

22. Fung LC, Khoury AE, McLorie GA, Chait PG, Churchill BM: Evaluation of pediatric hydronephrosis using individualized pressure flow criteria. J Urol. 1995; 154(2 Pt 2): 671-6.
23. Lupton EW, George NJ: The Whitaker test: 35 years on. BJU Int. 2010; 105: 94-100.

24. Vela-Navarrete R: Constant pressure flow-controlled antegrade pyelography. Eur Urol. 1982; 8: 265-8.

Correspondence address: Dr. Marcio Lopes Miranda University of Campinas - UNICAMP, Campinas Division of Pediatric Surgery, Genitourinary Division Cidade Universitária "Zeferino Vaz" Barão Geraldo, Campinas, 13083-970, SP, Brazil Fax: +55 19 3521-2121

E-mail: miranda@fcm.unicamp.br

\section{EDITORIAL COMMENT}

The authors should be congratulated for revisiting the results with a modification of the Whitaker test, in which has had loose popularity in the past decades. The authors described how many patients who maintain the hydronephrosis after upper urinary tract surgery will have a pelvic pressure higher than $14 \mathrm{cmH} 20$. This is important data.

Despite being an interesting study, it fails to validate Whitaker test or its modifications as a standard diagnosis test of obstruction after surgery. The endpoint used by the authors was the necessity of reoperation in cases of pyelic pressure above $14 \mathrm{~cm} \mathrm{H20}$. However, because we do not know the specificity of this method in humans we cannot rule out that in some cases the operation may be unnecessary. The best answer to the research question would be the improvement of renal dilatation in the long term.

In significant renal dilatations, there is failure of pelvic and calicial muscles because of the high intrarenal pressure before surgery. After corrective surgery, many children persist with the same renal dilatation as before (1). Methods to evaluate diagnosis that may better interpret theses cases are welcome. Renal scintigraphy with DTPA or MAG3 has a lot of limitations, and most of the time does not differentiate between obstruction and significant dilatation without obstruction. This exam commonly gives a false diagnosis of obstruction in very dilated kidneys. When the diuretic renogram is equivocal, usually there is no kidney obstruction. In this study, surgery was indicated for patients with an equivocal curve of obstruction. Furthermore, the authors reported that the test was performed in Grade II and III hydronephrosis. Usually, less than Grade IV hydronephrosis are not obstructed. Therefore, all these considerations suggest that, in this series, some patients could have been treated conservatively.

Whitaker test or its modifications might be useful sometime, however it cannot be considered the gold standard. It does not reproduce the pyelic physiology. It is not well demonstrated in humans to which pyelic pressure is associated to loss of kidney function. Therefore, the cutoff point of $14 \mathrm{cmH} 20$ for surgery indication is only a theory and should not be used as the only indication of reoperation. In my view, the best way to diagnosis urinary tract obstruction after surgery is by scintigraphic loss of kidney function and increase of hydronephrosis on ultrasound. The place of APA in the clinical practice is still obscure.

\section{REFERENCES}

1. Barroso U,Jr., Barroso VA, Calado A, Zerati M: Renal ultrasonographic findings before and after pyeloplasty. Int Braz $\mathrm{J}$ Urol 2000; 26: 190-5.

Dr. Ubirajara Barroso Jr. Federal University of Bahia Bahiana School of Medicine, Salvador, Bahia, Brazil E-mail:ubarroso@uol.com.br 